\title{
The Effect of Endocrinological Parameters on Sleep Quality, Life Quality, Depression and Anxiety Levels in Pregnancy
}

\author{
Filiz Ozsoy ${ }^{1}$ (D), Hatice Yilmaz Dogru² (D), Ilhan Bahri Delibas² (D) Aker Zeki Ozsoy² (D), Fazli Demirturk² \\ ${ }^{1}$ Tokat State Hospital, Department of Psychiatry, Tokat, Turkey \\ ${ }^{2}$ Gaziosmanpasa University, School of Medicine Department of Gynecology and Obstetrics, Tokat, Turkey \\ Correspondence Author: Filiz Ozsoy \\ E-mail: flzkoseoglu82@gmail.com
}

Received: $11.06 .2019 \quad$ Accepted: 06.12.2019

\begin{abstract}
Objectives: Examining the relation between sleep quality, quality of life, depression and anxiety levels with some endocrinological parameters in pregnancy.

Methods: The oral glucose loading test and thyroid function test results of the pregnant women who were in the 24-29th weeks of pregnancy were used in the study. Non-pregnant women, who were matched with the study group in terms of sociodemographic data, were also included in the study as the healthy control group. All participant completed a standardized sociodemographic data collection form and the following scales; Beck Depression Inventory (BDI), Beck Anxiety Inventory (BAI), Pittsburg Sleep Quality Scale (PDCA), Quality of Life Scale (SF-36).

Results: No significant differences were detected between the sociodemographic data of the participants except for the educational status and living area. As a result, statistically significant differences were detected between the "sleep latency" ( $p=0.016)$, "usual sleep activity" ( $p=0.004)$, "sleep disorder" ( $p=0.000$ ) subcomponents compared to the control group. For SF-36, on the other hand, the results of the pregnant group in "physical function" ( $p=0.000)$, "physical role limitation" ( $p=0.002)$ and "pain" ( $p=0.000)$ sub-dimensions were worse than the control group. The Thyroid Stimulating Hormone (TSH) value was positively correlated with "sleep time" ( $r=0.233$ ); the "fasting blood glucose" was positively correlated with "pain" sub-dimensions ( $r=0.497)$; and the "physical function" sub-dimension was negatively correlated $(r=-0.192)$.

Conclusion: Our data suggest that the depression and anxiety scores of the pregnant women were high, and life and sleep quality was impaired in certain sub-dimensions.
\end{abstract}

Keywords: Pregnancy, depression, anxiety, quality of life, quality of sleep.

\section{INTRODUCTION}

The term "life quality" is used as a unifying concept, which consists of numerous areas like personal development, self-acceptance, autonomy, purpose in life, positive social relations, the order of the living environment, and psychological and physical health $(1,2)$. The life quality of the individual may be affected by general health and social relations, personal beliefs and relations with his/her environment (3). Sleep which has an effect on the quality of life of the person is one of the basic and indispensable daily life activities, which influences the emotional status, general health and health perception of an individual, and is a physiological need for all humans. Sleep quality is affected by environmental factors like lifestyle, business life, social and economic status, and general health status (4).

Pregnancy is a transition period with significant physical and emotional changes (5). These changes, which occur even in healthy pregnant women, affect both the quality of life and sleep quality of the pregnant women and affect the health of both mother and baby $(6,7)$. In the light of the developments in mental health field, it was reported that psychiatric problems were common during pregnancy in the last 3 decades. Among the major ones of these problems, there are depressive disorder and anxiety disorder (8-11). The psychiatric symptoms that appear during pregnancy are attributed to hormonal and physical changes, and therefore, may go undetected. The psychiatric difficulties faced by the mother who is expecting her baby may cause negative effects on the physical and psychological development of the fetus. Also, a pregnant woman cannot prepare herself for role of a mother, life quality decreases, and conflicts may appear within the family (12). There are many studies in which the anxiety and depression levels of pregnant women are evaluated in the literature (12-15). However, studies that examine the quality of life, sleep quality, depression and anxiety levels are limited (16-20).

The aim of this study was to investigate the effect of endocrinological parameters on sleep quality, quality of life, depression and anxiety levels in pregnant women. Our first hypothesis in our study is that endocrinological parameters might be related with sleep and quality of life in pregnant 
women. Our second hypothesis is that endocrinological results and anxiety and depression levels might be correlated. Our final hypothesis is that the anxiety and depression levels of pregnant women may increase, and sleep quality and quality of life may be impaired independently from endocrinological functions. In the light of these hypotheses that are related to each other, it is considered that although there are no additional diseases, the rate of psychiatric symptoms (like anxiety and depressive symptoms) of pregnant women may increase, which might affect life and sleep quality scores. It was also hypothesized that the deterioration in one or more fields in endocrinological functions might cause more risks for psychiatric diseases. When considered from this viewpoint, having a good regulation in eating, drinking, physical activity and sleep, and psychosocial support are very important in terms of both the pregnancy period and the development of the baby.

\section{METHODS}

\subsection{Ethical procedure}

Approval was received for this study from Tokat Gaziosmanpaşa University Hospital, Non-Interventional Local Ethics Board and was carried out in line with the Helsinki Declaration.

\subsection{Inclusion and exclusion criteria}

The study was conducted Gaziosmanpaşa University Hospital between 05.03.2018 and 05.10.2018 as a case-control study. Pregnant women who volunteered, who were literate, able to give written informed consent and fill in the forms, and who did not have a history of psychiatric treatment, chronic renal failure, chronic liver disease, heart disease, diabetes mellitus and any known thyroid disease were included in the study. Approximately 300 randomly selected pregnant women who were at the 24-29 weeks of pregnancy were interviewed, informed about the study, and referred to the psychiatry outpatient clinic. However, only 164 pregnant women among these visited the psychiatrist, and were evaluated by the same psychiatrist. Forty-five of these pregnant women could not be included in the study; because of 13 women refused to participate in the study, 11 women did not fill in the forms and 21 women did not meet the criteria for inclusion in the trial. No data were collected from 136 women who did not come to the psychiatry outpatient clinic. The healthy control group participants was randomly selected from among women who were examined in the psychiatry outpatient clinic, and who did not have a disease to meet the criteria for diagnosis of mental health, and those who could be matched in terms of sociodemographic data like age, marital status, working status, and educational status. For this group, approximately 85 women were evaluated; however, 60 women met the inclusion criteria.

\subsection{Data collection tools}

The serum free $\mathrm{T}_{4}\left(\mathrm{sT}_{4}\right)$, Thyroid Stimulating Hormone (TSH), fasting blood sugar and glucose values after 75 gr glucose loading test were evaluated in the pregnant group. In addition, the Sociodemographic Data Form, Beck Depression Scale (BDS), Beck Anxiety Scale (BAS), Pittsburg Sleep Quality Scale (PSQS), Life Quality Scale (SF-36) were applied to all participants. The Socio-Demographic Data Form was applied during the interviews by psychiatrist and the other forms were filled in by the participants while they were waiting for the laboratory test results.

Sociodemographic Data Form: It was prepared in line with the clinical experience and the data obtained from the sources that were reviewed by considering the purpose of the study. It includes demographic data like age, marital status, educational status, living area, working status and economic status; and questions on clinical evaluation like the pregnancy week and whether or not the participant received psychiatric treatment before or during the study.

Beck Depression Scale (BDS): This is a self-report consisting of 21 items, and is used to determine the depression risk and to measure the level and severity of depressive symptoms. Each item is scored between 0 and 3; and the total score is between 0 and 63 . As the score becomes higher, this means that the person is experiencing higher depression $(21,22)$.

Beck Anxiety Scale (BAS): This consists of a total of 21 questions, and is used to measure the severity and level of anxiety symptoms. Each item is scored between 0 and 3 . As the score becomes higher, this means that the person is experiencing more anxiety. The highest score possible is $63(23,24)$.

Pittsburg Sleep Quality Scale (PSQS): This scale was developed by Buysse et al. (25); and is a self-report scale evaluating the sleep quality within the last 1 month. It consists of 19 questions and 7 components. It consists of "subjective sleep quality", "sleep latency", "sleep duration", "usual sleep activity", "sleep disorder", "sleep drug use" and "daytime function disorder" components. The scores of the 7 components and the total score are calculated. The total score being $\leq 5$ shows "good sleep quality", $>5$ shows "bad sleep quality" (26).

Life Quality Scale (SF-36): This is a self-report scale, which consists of eight sub-titles each having a total of 2-10 questions. The scale consists of "general health", "physical function", "physical role limitation", "emotional role limitation", "social function", "pain", "vitality/energy" and "mental health" subdimensions. Scoring varies between 0-100 for each subdimension. Low score means bad health status $(27,28)$.

\subsection{Statistical analyses}

Descriptive analyses were made to collect data on general characteristics of the participants. The data on continuous variables are given as mean \pm standard deviation; and the data on categorical variables are given as $n(\%)$. The qualitative variables of the study were the demographic data like age, educational status, socioeconomic status, and psychiatric treatment history, whether there was additional medical disease, and if there was, what the diagnosis was. The Cross-Table and Chi-Square Tests were made use of to evaluate the relations between the qualitative variables. 
The quantitative variables were the scores that obtained obtained from the applied scales and thyroid functions, fasting glucose values and glucose values measured after glucose loading test. The reference range of our hospital for laboratory parameters were; TSH: 0.27-4.6 ulU/ml; sT4: 0.93-1.7 ulU/ml; fasting blood glucose: $70-110 \mathrm{mg} / \mathrm{dl}$. For the 1 st hour:180 mg/dl; for 2 st hour:153 mg/dl. When the relations between the quantitative variables were evaluated, the Significance of the Difference Between Two Averages Test, One-Way Variance Analysis, and Pearson correlation coefficient were made use of. The scores obtained from the scales were calculated as the dependent variables, and the scores that were obtained from the laboratory parameters were calculated as the independent variables. When the $p$ values were calculated less than 0.05 , they were considered to be statistically significant. The SPSS for Windows 19

weeks of the pregnant women ranged between 24 and 29 weeks. The average age of the pregnant group was $25.55 \pm 5.14$ (17-38); and the average age of the healthy control group was $22.55 \pm 1.60$ (19-26). One participant was single in both groups. No significant differences were detected between the sociodemographic data of the participants except for the educational status and living area. None of the participants had psychiatric treatment history and additional medical disease before or during Software (Statistical Package for Social Sciences for Windows 19) was employed in the calculations.

\section{RESULTS}

A total of 119 pregnant women were included in the study, and 60 women were included as the healthy control group. The pregnancy the study period. The families of the participants did not receive any psychiatric treatment (Table 1 ).

Table 1. Sociodemographic characteristics of the participants.

\begin{tabular}{|l|c|c|c|}
\hline & $\begin{array}{c}\text { Pregnant Group } \\
\mathbf{N = 1 1 9}\end{array}$ & $\begin{array}{c}\text { Control Group } \\
\mathbf{N}=60\end{array}$ & $\mathbf{p}$ \\
\hline $\begin{array}{l}\text { Marital status } \\
\text { (Married/single) }\end{array}$ & $\begin{array}{c}\% \\
\text { 99.2/0.8 }\end{array}$ & $97.5 / 2.5$ & 0.972 \\
\hline $\begin{array}{l}\text { Living area } \\
\text { City center }\end{array}$ & 46.2 & 62.5 & 0.038 \\
Village & 53.8 & 37.5 & \\
\hline $\begin{array}{l}\text { Educational status } \\
\text { Primary school graduate }\end{array}$ & 2.5 & & \\
High school graduate & 68.1 & 3.0 & 0.025 \\
University graduate & 29.4 & 57.5 & \\
\hline Working status & & & \\
Regular/full-time job & 8.4 & 5.0 & 0.280 \\
Irregular/part-time job & 5.0 & 7.5 & \\
Housewife & 86.6 & 87.5 & \\
\hline Socioeconomic status & & & \\
Low & 22.7 & 5.0 & 0.228 \\
Moderate & 69.7 & 85.0 & \\
High & 7.6 & 10.0 & \\
\hline
\end{tabular}

None of the participants had received psychiatric treatment and additional medical diseases. Chi-square test was used. Values are presented as percentage (\%) in the table.
In the results of the participants that were analyzed with the Significance of the Difference Between Two Averages Test, it was determined that both BDS and BAS scores of the pregnant group were higher at a statistical level compared to the healthy control group (the $p$ values were calculated as $0.000 ; 0.004$, respectively). For PSQS, on the other hand, statistically significant differences were detected between "sleep latency", "usual sleep activity", "sleep disorder" subcomponents and the total score ( $p$ values were calculated as $0.016 ; 0.004 ; 0.000 ; 0.003$, respectively). For SF-36, the results of the pregnant group were worse than the control group in "physical function", "physical role limitation" and "pain" sub-dimensions ( $p$ values were $0.000 ; 0.002 ; 0.000$, respectively) (Table 2).

Table 2. Distribution of quantitative variables according to the groups

\begin{tabular}{|l|l|l|l|} 
Scale Applied & $\begin{array}{l}\text { Control Group } \\
\text { N=60 } \\
\text { (mean } \pm \text { SD) }\end{array}$ & $\begin{array}{l}\text { Pregnant Group } \\
\text { N=119 } \\
\text { (mean } \pm \text { SD) }\end{array}$ & P value \\
\hline TSH & & $1.8 \pm 0.94$ & \\
\hline sT4 & & $1.13 \pm 0.23$ & \\
\hline Fasting glucose & & $88.19 \pm 15.82$ & \\
\hline 75 gr glucose loading & & $123.59 \pm 32.89$ & \\
\hline Beck Depression Scale & $5.68 \pm 4.57$ & $8.19 \pm 6.19^{*}$ & 0.000 \\
\hline Beck Anxiety Scale & $9.10 \pm 9.11$ & $11.45 \pm 8.82^{*}$ & 0.004 \\
\hline Pittsburg Sleep Quality & & & \\
Scale & $0.98 \pm 0.70$ & $0.98 \pm 0.75$ & 1.000 \\
Subjective sleep quality & $0.93 \pm 0.83$ & $1.13 \pm 0.94^{*}$ & 0.016 \\
Sleep latency & $0.23 \pm 0.48$ & $0.42 \pm 0.78$ & 0.805 \\
Sleep duration & $0.18 \pm 0.38$ & $0.58 \pm 0.79 *$ & 0.004 \\
Decreased sleep activity & $1.03 \pm 0.62$ & $1.50 \pm 0.76^{*}$ & 0.000 \\
Sleep disorder & $0.13 \pm 0.40$ & $0.08 \pm 0.36$ & 0.262 \\
Sleep drug & $0.85 \pm 0.92$ & $0.76 \pm 0.83$ & 0.817 \\
Daytime function loss & $6.60 \pm 1.30$ & $5.40 \pm 2.87$ & 0.003 \\
Total score & & & \\
\hline Life quality scale & & & \\
Physical function & $85.62 \pm 28.49$ & $53.40 \pm 24.69^{*}$ & 0.000 \\
Physical role limitation & $68.75 \pm 38.71$ & $47.73 \pm 36.63^{*}$ & 0.002 \\
Emotional role limitation & $60.40 \pm 43.31$ & $51.99 \pm 37.63$ & 0.199 \\
Vitality & $49.38 \pm 19.59$ & $54.71 \pm 20.65$ & 0.240 \\
Mental health & $58.95 \pm 18.75$ & $61.22 \pm 19.36$ & 0.095 \\
Social function & $71.37 \pm 23.36$ & $68.77 \pm 22.13$ & 0.063 \\
Pain & $73.62 \pm 18.62$ & $55.06 \pm 20.94^{*}$ & 0.000 \\
General health & $60.13 \pm 18.66$ & $57.44 \pm 18.33$ & 0.204 \\
\hline
\end{tabular}

Mean $\pm S D=$ Mean \pm Standard deviation. The Significance of the Difference Between Two Averages Test was used. ${ }^{*} P<0.05$

The Pearson Correlation Analysis results of the scales that were applied in the present study are presented in the tables (Table 3 and Table 4). Although BDS and SF-36 were negatively correlated; certain sub-dimensions of PSQS were positively correlated and sleep quality worsened as depression scores increased. Similarly, BAS and PSQS were positively correlated and SF-36 was negatively correlated. In our results, some subdimensions of PSQS and SF-36 were shown to be negatively correlated (Table 3, 4). 
Table 3. Life quality and sleep quality Pearson Correlation Analysis results

\begin{tabular}{|c|c|c|c|c|c|c|c|c|}
\hline \multirow[t]{2}{*}{ SF-36 } & \multicolumn{8}{|c|}{ Pittsburg Sleep Quality Scale (R value) } \\
\hline & PSQS-1 & PSQS-2 & PSQS-3 & PSQS-4 & PSQS-5 & PSQS-6 & PSQS-7 & PSQS - Total \\
\hline $\begin{array}{l}\text { Physical } \\
\text { function }\end{array}$ & -.146 & -.099 & -.131 & -.148 & -.131 & -.039 & -.021 & -.174 \\
\hline $\begin{array}{l}\text { Physical role } \\
\text { Limitation }\end{array}$ & $-.277^{*}$ & -.157 & .064 & -.047 & $-.300 *$ & .111 & $-.224^{*}$ & $-.255^{*}$ \\
\hline $\begin{array}{l}\text { Emotional } \\
\text { role limitation }\end{array}$ & -.155 & -.100 & -.041 & -.039 & $-.361^{*}$ & -.075 & -.003 & $-.202^{*}$ \\
\hline Vitality & $-.269 *$ & -.202 & -.103 & -.167 & $-.359 *$ & -.140 & $-.233^{*}$ & $-.381^{*}$ \\
\hline Mental health & $-.200 *$ & $-.244^{*}$ & -.172 & $-.179 *$ & $-.299 *$ & -.022 & $-.242^{*}$ & $-.345^{*}$ \\
\hline Social function & $-.277^{*}$ & $-.212^{*}$ & -.079 & $-.181^{*}$ & $-.483 *$ & -.023 & $-.323^{*}$ & $-.420 *$ \\
\hline Pain & -.013 & -.023 & -.062 & .039 & .042 & -.022 & -.094 & -.034 \\
\hline General Health & .053 & $-.184^{*}$ & -.040 & -.152 & $-.324 *$ & -.122 & -.155 & $-.252 *$ \\
\hline
\end{tabular}

SF-36: Life Quality Scale; PSQS: Pittsburg Sleep Quality Scale ; 1:"subjective sleep quality"; 2: "sleep latency"; 3: "sleep duration"; 4: "usual sleep activity"; 5:"sleep disorder"; 6:sleep drug take"; 7: daytime function disorder". Pearson correlation analysis results, the values in the table are " $r$ " values. * $P<0.05$.

Table 4. Relation of Beck Depression Scale and Beck Anxiety Scale scores with sleep and life quality

\begin{tabular}{|l|c|c|c|c|} 
& \multicolumn{2}{|c|}{ Beck Depression Scale } & \multicolumn{2}{c|}{$\begin{array}{c}\text { Beck Anxiety } \\
\text { Scale }\end{array}$} \\
\cline { 2 - 5 } & R value & P value & R value & P value \\
\hline Pittsburg sleep quality scale & & & \\
\hline PSQS-1 & $0.296^{*}$ & 0.001 & $0.181^{*}$ & 0.049 \\
\hline PSQS-2 & $0.266^{*}$ & 0.004 & $0.197^{*}$ & 0.032 \\
\hline PSQS-3 & $0.248^{*}$ & 0.007 & 0.161 & 0.081 \\
\hline PSQS-4 & 0.269 & 0.003 & $0.237^{*}$ & 0.009 \\
\hline PSQS-5 & $0.315^{*}$ & 0.000 & $0.409^{*}$ & 0.000 \\
\hline PSQS-6 & 0.107 & 0.246 & -0.071 & 0.443 \\
\hline PSQS-7 & 0.178 & 0.052 & $0.219^{*}$ & 0.017 \\
\hline PSQS-total & $0.451^{*}$ & 0.000 & $0.378^{*}$ & 0.000 \\
\hline Life quality scale & & & & \\
\hline Physical function & $-0.226^{*}$ & 0.013 & $-0.302^{*}$ & 0.001 \\
\hline Physical role limitation & $-0.303^{*}$ & 0.001 & $-0.379^{*}$ & 0.000 \\
\hline Emotional role limitation & $-0.374^{*}$ & 0.000 & $-0.413^{*}$ & 0.000 \\
\hline Vitality & $-0.498^{*}$ & 0.000 & $-0.464^{*}$ & 0.000 \\
\hline Mental health & $-0.514^{*}$ & 0.000 & $-0.363^{*}$ & 0.000 \\
\hline Social function & $-0.388^{*}$ & 0.000 & $-0.492^{*}$ & 0.000 \\
\hline Pain & 0.034 & 0.712 & -0.035 & 0.707 \\
\hline General health & $-0.356^{*}$ & 0.000 & $-0.350^{*}$ & 0.000 \\
\hline
\end{tabular}

PSQS: Pittsburg Sleep Quality Scale ; 1:"subjective sleep quality"; 2: "sleep latency"; 3: "sleep duration"; 4:"usual sleep activity"; 5:"sleep disorder"; 6:sleep drug take";7: "daytime function disorder". Pearson correlation analysis results; ${ }^{*} P<0.05$.
The TSH values of only one participant were higher $(0.84 \%)$ than the normal range $(4.850 \mathrm{ulU} / \mathrm{ml})$, the sT4 value of all participants was within the normal range. The fasting blood sugar values of 10 participants $(8.40 \%)$ were higher than the normal range. It was determined that the blood glucose levels of 24 participants in the first hour after 75 gr glucose loading were higher than the expected values. However, it was also determined that these values decreased to the normal limits at the second and third hours in all pregnant women. The values of the other pregnant women were within normal limits. The TSH value, which is one of the thyroid functions, showed a positive correlation with sleep duration ( $r: 0.233)$. Although the fasting blood sugar values and the SF-36 "physical function" sub-dimension were negatively correlated ( $r$ :-.0.192), the "pain" sub-dimension was positively correlated ( $r: 0.497)$ (Table 5).

\section{DISCUSSION}

In our study, in which the relations between sleep and life quality of pregnant women and endocrinological functions were investigated, it was determined that there were deteriorations in the sleep and life quality scores of pregnant women in certain sub-dimensions. In addition to this, it was

Table 5. The correlation of thyroid function and blood sugar values with anxiety-deppressive scores and sleep-life quality

\begin{tabular}{|c|c|c|c|c|c|c|c|c|c|c|c|c|c|c|c|c|}
\hline & \multicolumn{7}{|c|}{ Pittsburg Sleep Quality Scale } & \multicolumn{7}{|c|}{ Life Quality Scale } & \multirow{2}{*}{ BAS } & \multirow{2}{*}{ BDS } \\
\hline & 1 & 2 & 3 & 4 & 5 & 6 & 7 & 1 & 2 & 3 & 4 & 5 & 6 & 7 & & \\
\hline $\mathrm{SH}$ & .061 & .131 & -.092 & .030 & .025 & -.050 & -.010 & -.013 & .018 & .015 & .101 & .018 & .011 & -.032 & -079 & -.001 \\
\hline $\mathrm{sT}_{4}$ & -.030 & .019 & $233^{*}$ & .085 & .011 & .073 & .028 & .080 & .083 & .037 & .049 & .039 & .054 & -.074 & .001 & -.022 \\
\hline FBS & .109 & .087 & -.116 & -.058 & -.156 & -.101 & .032 & -192 & -.144 & -.030 & -.137 & -.013 & -.143 & $.497 *$ & .034 & .095 \\
\hline 75 gr GLT & .031 & -.005 & -.034 & .127 & .047 & .047 & .098 & -.045 & -.091 & .040 & -.075 & .146 & .108 & $.335^{*}$ & .000 & -.017 \\
\hline
\end{tabular}

PSQS: Pittsburg Sleep Quality Scale ; 1:"subjective sleep quality"; 2: "sleep latency"; 3: "sleep duration"; 4:"usual sleep activity" 5:"sleep disorder"; 6:"sleep drug take"; $7:$ "daytime function disorder"

Life Quality scale; 1: "Physical function"; 2: "Physical role limitation"; 3: "Emotional role limitation"; 4:"Vitality"; 5: "Mental health"; 6: "Social function"; 7: "Pain"

ST4 : free thyroxin, TSH: thyroid stimulant hormone; FBS: Fasting blood sugar; 75 gr GLT: 75 gr glucose loading test.

Pearson correlation analysis results, the values in the table are " $r$ " values. ${ }^{*} P<0.05$ 
also determined that the depression and anxiety scores of the pregnant group were higher than the Control Group.

Psychiatric symptoms may go undetected with the effect of hormonal and physical changes during pregnancy. In the literature, in previous studies that were conducted in the last 20 years, depressive disorder and anxiety disorder, which are among psychiatric diseases during pregnancy, rank the first (8-16). It was even shown in some studies that depression and anxiety levels of pregnant women could be interrelated with demographic characteristics like age, marital status, education level, socioeconomic status and residence $(13,14)$. In our results, no correlations were detected between the depression scale, anxiety scale scores and sociodemographic data. No significant relations were detected between depression and anxiety levels and any endocrinological parameters in our study. Depression scores and anxiety scores, on the other hand, showed positive correlation with each other, which is consistent with the literature (9-11,1316). It was seen that depression levels increased in a pregnant woman if she had high anxiety levels, and also, anxiety levels increased in a pregnant woman if she had high depression levels.

In terms of sleep quality, a deterioration was detected between the "sleep latency", "usual sleep activity", "sleep disorder" sub-components and total scores, compared to the controls. In studies conducted on the sleep quality of women, it was shown that many young women experienced sleep disorder $(17,18)$. When the literature is examined, it is seen that many studies show that sleep quality is impaired in pregnant women. This situation was attributed to many factors like weight gain during pregnancy, insufficient physical activity, fetal growth, pain, cramps and hormonal changes $(19,20,29,30)$. In our results, no significant relations were detected between fasting blood sugar, glucose loading values and PSQS sub-dimensions or total scores. In the literature, it was shown in a study that sleep quality was worse in pregnant women who had higher fasting glucose levels. In the same study the hemoglobin A1c values were measured and it was determined that the sleep quality of pregnant women who had high hemoglobin A1c was worse (29). In another retrospective study, it was reported that the blood sugar values of pregnant women who had impaired sleep quality and low sleep periods were more likely to be higher (31). Although no positive and significant relations were detected between PSQS and blood sugar values in our results, it was determined that "sleep duration", "usual sleep activity" and "taking sleep drugs" sub-dimensions were negatively related in the correlation analyses results. In terms of thyroid functions, only ST4 values and "sleep duration" were found to be interrelated. In our results, none of the subdimensions and total scores of PSQS were found to be interrelated with sociodemographic data. In some studies in the literature, it was found that as age furthered, and as education level decreased, sleep quality scores were found to be worsened in unplanned pregnancies and in patients who had other diseases that accompanied pregnancy (16).
The pregnant women received lower scores than control group in almost all sub-dimensions in our results. In other words, non-pregnant people had poor life quality in all subdimensions. But statistically significant scores were detected in "physical function", "physical role limitation" and "pain" sub-dimensions. A great number of studies were conducted in the past using different life quality scales in pregnant women. In another study with SF-36, the quality of life scores in areas other than "mental health" and "pain" sub-dimensions was calculated as low. The quality of life scores in participants who had diseases that accompanied pregnancy, who had high number of total pregnancies, high number of children and high number of individuals living in the family were found to be poorer (16). In another study that was conducted by examining PUBMED and COCHRANE references, it was determined that the quality of life was impaired in general although there were no objective measurement tools for the quality of life in pregnant women. Meanwhile, it was determined that pregnant women showed more depressive symptoms in psychiatric terms (32). In a study that evaluated quality of life with the Nottingham Health Profile, it was determined that physical activities of pregnant women were negatively related to their life quality (33). In our results, a negative relation was determined in all parameters except life quality "pain" sub-dimension and anxiety and depression levels were. In other words, it was determined that as the scores of depression and anxiety increased, the quality of life scores became impaired. In a study in which SF-36 was used on two different groups of pregnant women with and without depression, it was found that the pregnant women had poor life quality scores. It was determined that the life qualities and especially "mental health", "vitality" and "social function" sub-dimensions of pregnant women who are diagnosed with depressive disorder were much worse (34). Sleep quality and life quality were found to be inversely related in many fields. It was observed that as the life quality, "physical role limitation", "physical role limitation", "emotional role limitation", "vitality", "mental health", "social function" and "general health" became impaired, $\mathrm{d}$-so did the sleep quality. It was reported in many studies in the literature that as sleep quality deteriorated, life quality became also impaired $(16,34-36)$. In our result, no significant relations were detected between thyroid functions and any of the subdimensions of life quality. The fasting blood sugar values were related negatively with "physical function", and positively with "pain" sub-dimension.

In a study investigating the life and sleep quality scores of pregnant women with high risks (pregnant women diagnosed with diabetes and hypertension), it was determined that sleep and life quality were impaired (35). In a study that was conducted on life quality and problem-solving skills of diabetes patients, no relations were detected between blood sugar and hemoglobin A1c levels and life quality. It was observed in the same study that there was a negative relation between the functional problem-solving styles of diabetics and HbA1c (37). In another study that was conducted in diabetic patients, no relations were detected 
between blood sugar levels and quality of life. However; demographic characteristics like education level, economic status and duration of diabetes had significant correlations with life quality (38). In our results, no relations were detected between sociodemographic data and life quality scores.

Our results must be evaluated by considering some limitations. The first one of the limitations is that the sample size was relatively small. Also, the study was conducted with the scales that were filled by the participants themselves; and the pregnant women in a single trimester period were evaluated. These limitations avoid that our findings are generalized. Further studies are required to examine more pregnant women in larger sampling groups who are at different gestational periods with larger laboratory parameters.

As a result; our first hypothesis in our study was that endocrinological results might be related with sleep and quality of life in pregnant women. However, we did not find any relationship between thyroid functions and quality of life in the results we obtained. In terms of sleep quality, it was determined that only the "sleep time" was associated with thyroid functions. In terms of blood sugar values, although a relation was not detected with sleep quality, it was determined that there was a positive correlation between "physical function" sub-dimension, and a negative correlation with "pain" sub-dimension. Our second hypothesis was that endocrinological results could have relations with anxiety and depression levels. However, our results did not confirm this hypothesis. It was determined that there were no relations between depression and anxiety levels and blood parameters. Our last hypothesis was that the anxiety and depression levels of pregnant women might increase and sleep quality and quality of life may be impaired independently from endocrinological functions. Our results confirmed this hypothesis. It was determined that the depression and anxiety scores of pregnant women were high, and sleep and quality of life were impaired in certain subcomponents. It was considered that sleep and life quality might be impaired with the changing hormonal values, weight, eating and physical activity in pregnancy. When many pregnant women are considered from this point of view, it becomes obvious that they must be collaborates with multiple disciplines like gynecologist and obstetrician, dieticians, psychiatrists to have a more comfortable and healthy pregnancy.

\section{REFERENCES}

[1] Bie'n A, Rzo'nca E, Ka'nczugowska A, IwanowiczPalus G. Factors affecting the quality of life and the illness acceptance of pregnant women with diabetes. Int J Environ Res Public Health 2015; 13(1): 68.

[2] Ryff CD. Psychological well-being revisited: advances in the science and practice of eudaimonia. Psychother Psychosom 2014; 83: 10-28.

[3] Group TW. The World Health Organization quality of life assessment (WHOQOL): development and general psychometric properties. Social Sci Med 1998; 46(12): 15691585.

[4] Barion A, Zee PC. A clinical approach to circadian rhythm sleep disorders. Sleep Med 2007; 8(6): 566-577.

[5] Bourgoin E, Callahan S, Séjourné N, Denis A. Body self-esteem and pregnancy: Subjective experiences in 12 women. An exploratory mixed-methods study. Psychol Fr 2012; 57: 205213.

[6] Diego MA, Field T, Hernandez-Reif M, Cullen C, Schanberg $\mathrm{S}$, Kuhn C. Prepartum, postpartum, and chronic depression effects on newborns. Psychiatry 2004; 67: 63-80.

[7] Ibanez G, Blondel B, Prunet C, Kaminski M, Saurel-Cubizolles MJ. Prevalence and characteristics of women reporting poor mental health during pregnancy: findings from the 2010 French National Perinatal Survey. Rev Epidemiol Sante Publique 2015; 63: 85-95.

[8] Yılmaz SD, Benli NK. Levels of coping with stres, depression and prenatal attachment and affecting factors of pregnant women. J General Medical 2010; 20(3): 98-103 (in Turkish).

[9] Yücel P, Çayır Y, Yücel M. Depression and Anxiety Among First Trimester Pregnancies. J Clin Psychiatr 2013; 16: 83-87.

[10] Dağlar G, Nur N. The relationship between anxiety and depression level and coping styles with stress of pregnant women. J Med Cumhuriyet 2014; 36(4): 429-441 (in Turkish).

[11] Tunç S, Yenicesu O, Çakar E, Özcan H, Pekçetin S, Danışman N. Anxiety and depression frequency and related factors during pregnancy. J Gynecol Obstet Neonatol 2012; 9: 1431-1435.

[12] Çalık KY, Aktaş S. Depression in Pregnancy: Prevalence, Risk Factors and Treatment. C Ap Psy 2011; 3(1): 142-162 (in Turkish).

[13] Figueiredo B, Conde A. Anxiety and depression in women and men from early pregnancy to 3-months postpartum. Arch Womens Ment Health 2011; 14(3): 247-255.

[14] Dağlar G, Bilgiç D, Koç S, Yörük B, Çoşkun P. Anxiety and depression levels of women's pre and post-labor stage and influencing factors. I J MHS 2016; 6(4): 114-120.

[15] Zaman FK, Özblood N, Toprak D. Depression and Anxiety in Pregnancy. J Med Konuralp 2018; 10(1): 20-25 (in Turkish).

[16] Özhüner $Y$, Çelik N. Sleep Quality and Quality of Life in Pregnants. HSP 2019; 6(1): 25-33.

[17] Mehta N, Shafi F, Bhat A. Unique Aspects of Sleep in Women. Mo Med 2015; 112: 430-434.

[18] Tamanna S, Geraci SA. Major sleep disorders among women. South Med J 2013; 106: 470-478.

[19] Herring SJ, Nelson DB, Pien GW, Homko C, Goetzl LM, Davey A, Foster GD. Objectively measured sleep duration and hyperglycemia in pregnancy. Sleep Med 2014; 15(1): 51-55.

[20] Hawkins M, Marcus B, Pekow P, Rosal MC, Tucker KL, Spencer RM, Chasan-Taber L. Physical Activity and Sleep Quality and Duration During Pregnancy Among Hispanic Women: Estudio PARTO. Behav Sleep Med 2018; 17(6): 804-817.

[21] Beck AT, Ward CH, Mendelson M, Mock J, Erbaugh J. An inventory for measuring depression. Arch Gen Psychiatry 1961; 4: 561-571.

[22] Hisli-Sahin N. A study on the validity of the Beck Depression Inventory. Turkish J Psychol 1988; 6: 118-126 (in Turkish).

[23] Beck AT, Epstein N, Brown G, Ster RA. An inventory for measuring clinical anxiety: psychometric properties. J Consul Clin Psychol 1988; 56: 893-897. 
[24] Ulusoy M, Şahin NH, Erkmen H. Turkish version of the Beck Anxiety Inventory: Psychometric properties. J Cog Psychother 1988; 12: 163-172.

[25] Buysse DJ, Reynolds CF 3rd, Monk TH, Berman SR, Kupfer DJ. The Pittsburgh Sleep Quality Index: a new instrument for psychiatric practice and research. Psychiatry Res 1989; 28(2): 193-213.

[26] Agargun MY, Kara H, Anlar O. Validity and reliability of Pittsburg sleep quqlity index. Turkish J Psychiatry 1996; 7(2): 107-115 (inTurkish).

[27] Ware Jr JE, Sherbourne CD. The MOS 36-item short-form health survey (SF-36): I. Conceptual framework and item selection. Med Care. 1992: 473-483.

[28] Koçyigit $\mathrm{H}$. Reliability and validity of Turkish version of the Short Form-36 (SF-36). J Drug Ther 1999; 12: 102-106 (in Turkish).

[29] Chirwa S, Nwabuisi C, Ladson G, Korley L, Whitty J, Atkinson R, Clark JT. Poor Sleep Quality Is Associated with Higher Hemoglobin A1c in Pregnant Women: A Pilot Observational Study. Int J Environ Res Public Health 2018; 15(10): 2287.

[30] Gay CL, Richoux SE, Beebe KR, Lee KA. Sleep disruption and duration in late pregnancy is associated with excess gestational weight gain among overweight and obese women. Birth 2017; 44(2): 173-180.

[31] Reutrakul S, Anothaisintawee T, Herring SJ, Balserak BI, Marc I, Thakkinstian A. Short sleep duration and hyperglycemia in pregnancy: Aggregate and individual patient data metaanalysis. Sleep Med Rev 2018; 40: 31-42.
[32] Morin M, Vayssiere C, Claris O, Irague F, Mallah S, Molinier L, Matillon $Y$. Evaluation of the quality of life of pregnant women from 2005 to 2015. European J Obstet Gynecol Reprod Biol 2017; 214: 115-130.

[33] Özdemir ÖÇ, Sürmeli M, Özel A, Yavuz IE, Topçuoğlu A, Ankaralı $\mathrm{H}$. The relationship between physical activity and quality of life in pregnant women. Anatolian Clinic J Med Sci 2017; 22(2): 95102 (in Turkish).

[34] Abbaszadeh F, Atrian MK, Alavi NM, Bagheri A, Sadat Z, Karimian Z. Relationship between quality of life and depression in pregnant women. Nurs Midwifery Stud 2013; 2(2): 193.

[35] Saadati F, Sehhatiei-Shafaei F, Mirghafourvand M. Sleep quality and its relationship with quality of life among high-risk pregnant women (gestational diabetes and hypertension). J Maternal-Fetal-Neonatal Med 2018; 31(2): 150-157.

[36] Effati-Daryani F, Mirghafourvand M, Mohammad-Charandabi $S$, Shiri-Sarand F, Zarei S. Sleep quality and its relationship with quality of life in Iranian pregnant women. Int J Nurs Prac 2017; 23(2): e12518.

[37] Başer SÖ, Özcan S. Relationship between social problemsolving styles/orientations, quality of life and $\mathrm{HbA1c}$ levels in diabetic patients. Çukurova Med J 2018; 43(3): 660-668 (in Turkish).

[38] Parsa P, Ahmadinia-Tabesh R, Mohammadi $Y$, Khorami N. Investigating the relationship between quality of life with lipid and glucose levels in Iranian diabetic patients. Diabetes and Metabolic Syndrome. Clin Res Rev 2017; 11: 879-883. 